Research Article

\title{
Theoretical Analysis of Effects of Wall Suction on Entropy Generation Rate in Laminar Condensate Layer on Horizontal Tube
}

\author{
Tong-Bou Chang ${ }^{1,2}$ \\ ${ }^{1}$ Department of Mechanical and Energy Engineering, National Chiayi University, No. 300, Syuefu Road, Chiayi City 600, Taiwan \\ ${ }^{2}$ Center of Energy Research \& Sensor Technology, National Chiayi University, No. 300, Syuefu Road, Chiayi City 600, Taiwan \\ Correspondence should be addressed to Tong-Bou Chang; tbchang@mail.ncyu.edu.tw
}

Received 28 August 2014; Revised 11 November 2014; Accepted 17 November 2014; Published 4 December 2014

Academic Editor: Hang Xu

Copyright (C) 2014 Tong-Bou Chang. This is an open access article distributed under the Creative Commons Attribution License, which permits unrestricted use, distribution, and reproduction in any medium, provided the original work is properly cited.

\begin{abstract}
The effects of wall suction on the entropy generation rate in a two-dimensional steady film condensation flow on a horizontal tube are investigated theoretically. In analyzing the liquid flow, the effects of both the gravitational force and the viscous force are taken into account. In addition, a film thickness reduction ratio, $S_{f}$, is introduced to evaluate the effect of wall suction on the thickness of the condensate layer. The analytical results show that, the entropy generation rate depends on the Jakob number Ja, the Rayleigh number $\mathrm{Ra}$, the Brinkman number $\mathrm{Br}$, the dimensionless temperature difference $\psi$, and the wall suction parameter $S_{w}$. In addition, it is shown that in the absence of wall suction, a closed-form correlation for the Nusselt number can be derived. Finally, it is shown that the dimensionless entropy generation due to heat transfer, $N_{T}$, increases with an increasing suction parameter $S_{w}$, whereas the dimensionless entropy generation due to liquid film flow friction, $N_{F}$, decreases.
\end{abstract}

\section{Introduction}

Film condensation on a horizontal tube has many thermal engineering applications, including chemical vapor deposition, distillation, and heat exchange. The problem of laminar film condensation flow was first investigated by Nusselt [1], who considered the case of film condensation on a vertical plate. The results showed that a local balance existed between the viscous force and the weight of the condensate film provided that three simplifying assumptions were satisfied; namely, (1) the condensate film was very thin, (2) the convective and inertial effects were very small, and (3) the temperature within the condensate layer varied linearly over the film thickness. In later studies, researchers investigated the laminar film condensation of quiescent vapors under more realistic assumptions [2-5]. Yang and Chen [6] investigated the effects of surface tension and ellipticity on laminar film condensation on a horizontal elliptical tube. The results showed that the heat transfer coefficient increased with an increasing surface tension force and tube ellipticity. Hu and Chen [7] investigated the problem of turbulent film condensation on an inclined elliptical tube and found that the heat transfer performance improved as the vapor velocity increased. Additionally, it was shown that a circular tube resulted in a higher heat transfer coefficient than an elliptical tube.

Irreversibilities due to heat transfer and friction inevitably exist in practical thermal systems. This phenomenon, referred to as entropy generation, reduces the energy available to perform work and should therefore be minimized. Bejan [8] proposed a method for minimizing entropy generation in such key applications as power generation, refrigeration, and energy conservation. Bejan [9] also conducted a second law thermodynamics analysis of the entropy generation minimization problem for single-phase convection heat transfer. The same author [10] devised effective methods for minimizing entropy generation in heat transfer systems consisting of flat plates or cylinders placed in a crossflow. Saouli and Aïboud-Saouli [11] performed a second law thermodynamic 
analysis of the convection heat transfer problem in singlephase falling liquid film flow along an inclined heated plate. In investigating the problem of heat transfer with phasechange, Adeyinka and Naterer [12] analyzed the entropy generation and energy availability in vertical film condensation heat transfer. The results indicated that entropy generation provides a useful parameter for optimizing two-phase systems. Dung and Yang [13] applied the entropy generation minimization method proposed by Bejan in [8] to optimize film condensation heat transfer on a horizontal tube. Their results showed that the optimal group Rayleigh parameter exists over the parametric range investigated for horizontal tube at which the entropy is generated at a minimum rate. $\mathrm{Li}$ and Yang [14] applied the entropy generation minimization method to optimize the heat transfer performance of a horizontal elliptical cylinder in a saturated vapor flow. In a recent study, Chang and Wang [15] investigated the heat transfer characteristics and entropy generation rate of a condensate film on a horizontal plate and found that the overall entropy generation rate induced by the heat transfer irreversibility effect is equivalent to the Nusselt number.

The problem of laminar film condensation with wall suction effects has been widely discussed in the literature [1618]. In general, the results have shown that wall suction significantly enhances the condensation heat transfer performance. However, the literature lacks a systematic investigation into the effects of wall suction on the entropy generation rate in laminar film condensation on a horizontal tube. Accordingly, the present study performs an analytical investigation into the effects of the Jakob number, Rayleigh number, Brinkman number, dimensionless temperature difference, and suction force on the dimensionless entropy generation rate for a horizontal tube in a stationary saturated vapor. Notably, in performing the analysis, the effects of both the gravitational force and the viscous force are taken into explicit account.

\section{Analysis}

Consider a pure vapor in a saturated state condensing on a horizontal and permeable tube (see Figure 1). Assume that the vapor has a uniform temperature $T_{\text {sat }}$ and the tube (with diameter $D$ ) has a constant wall temperature $T_{w}$. If $T_{\text {sat }}$ is higher than $T_{w}$, a thin liquid condensate-layer is formed on the surface of the tube. In analyzing the heat transfer characteristics of the condensate film, the same assumptions as those used by Rohsenow [19] are applied; namely, (1) the condensate film flow is steady and laminar, and thus the effects of inertia and convection can be ignored (i.e., a creeping film flow is assumed); (2) the wall temperature, vapor temperature, and properties of the dry vapor and condensate, respectively, are constant; and (3) the condensate film has negligible kinetic energy. Consequently, the governing equations for the condensate layer can be formulated as follows:

continuity equation:

$$
\frac{\partial u}{\partial x}+\frac{\partial v}{\partial y}=0
$$

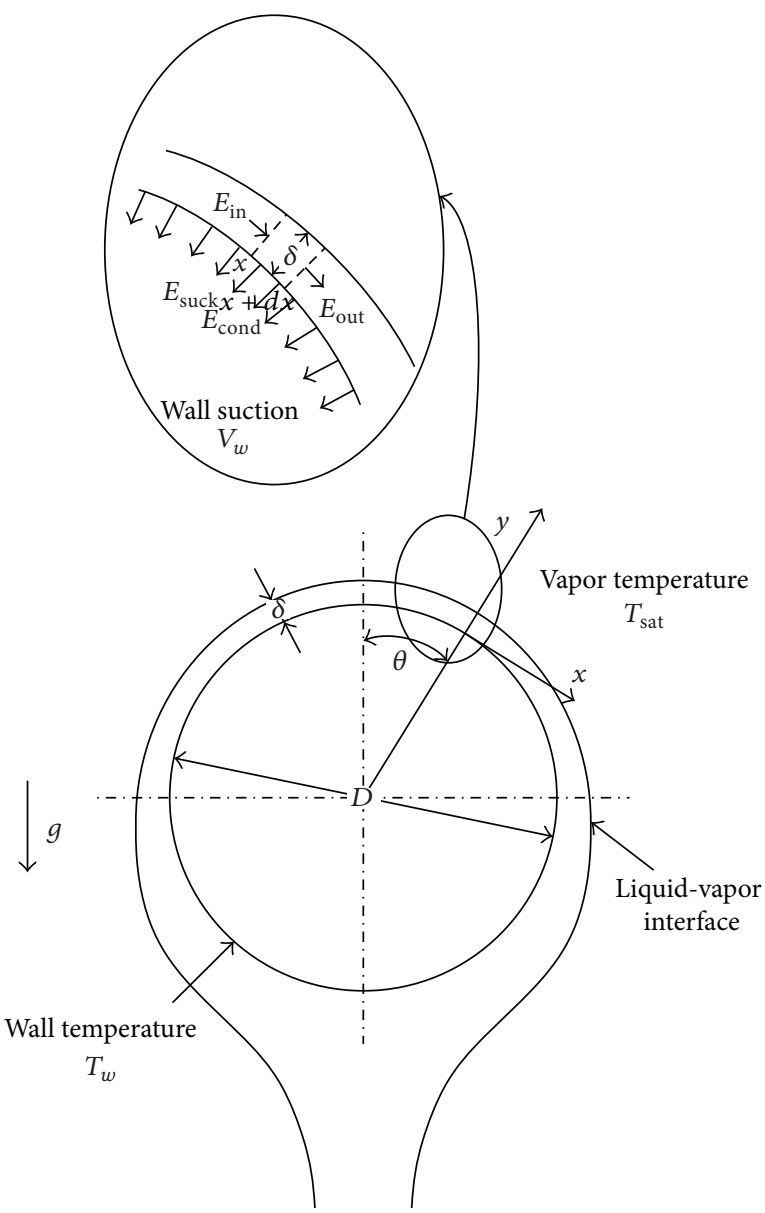

Figure 1: Physical model.

momentum equation:

$$
0=\mu \frac{\partial^{2} u}{\partial y^{2}}+\left(\rho-\rho_{v}\right) g \sin \theta
$$

energy equation:

$$
0=\alpha \frac{\partial^{2} T}{\partial y^{2}}
$$

In (1)-(3), the $(x, y)$ coordinates are local coordinates and are used specifically to simplify the governing equations. The local coordinate frame $(x, y)$ and cylindrical coordinate frame $(r, \theta)$ are related as $x=(D / 2) \theta$ and $y=r-(D / 2)$. The boundary conditions are given as follows:

at the tube surface, that is, $y=0$,

$$
v=v_{w}, \quad T=T_{w} ;
$$

at the liquid-vapor interface, that is, $y=\delta$,

$$
T=T_{\text {sat }}
$$


Integrating the momentum equation given in (2) using the boundary conditions given in (4) and (5), the velocity distribution within the condensate film is obtained as

$$
u=\frac{\left(\rho-\rho_{v}\right) g \sin \theta}{\mu}\left(\delta y-\frac{1}{2} y^{2}\right) .
$$

Meanwhile, integrating the energy equation given in (3) using the boundary conditions given in (4) and (5), the temperature profile is obtained as

$$
T=T_{w}+\Delta T \frac{y}{\delta}
$$

Utilizing the second law approach proposed by Bejan [8], the local entropy generation equation for the convection heat transfer within the condensate film is given as

$$
\begin{aligned}
S^{\prime \prime} & =\frac{k}{T_{w}^{2}}\left[\left(\frac{\partial T}{\partial x}\right)^{2}+\left(\frac{\partial T}{\partial y}\right)^{2}\right]+\frac{\mu}{T_{w}}\left(\frac{\partial u}{\partial y}\right)^{2} \\
& =S_{T}^{\prime \prime}+S_{F}^{\prime \prime}
\end{aligned}
$$

where $k$ is the thermal conductivity of the liquid condensate.

The local entropy generation equation contains two components, namely, the entropy generation due to heat transfer, $S_{T}^{\prime \prime}$, and the entropy generation due to fluid friction, $S_{F}^{\prime \prime}$. From $(8), S_{T}^{\prime \prime}$ and $S_{F}^{\prime \prime}$ are defined, respectively, as

$$
\begin{gathered}
S_{T}^{\prime \prime}=\frac{k}{T_{w}^{2}}\left[\left(\frac{\partial T}{\partial x}\right)^{2}+\left(\frac{\partial T}{\partial y}\right)^{2}\right] \\
S_{F}^{\prime \prime}=\frac{\mu}{T_{w}}\left(\frac{\partial u}{\partial y}\right)^{2} .
\end{gathered}
$$

Substituting the velocity distribution in (6) and the linear temperature profile in (7) into (9) and (10), the local entropy generation due to heat transfer and fluid friction can be rewritten, respectively, as

$$
\begin{gathered}
S_{T}^{\prime \prime}=\frac{k}{T_{w}^{2}}\left(\frac{\Delta T}{\delta}\right)^{2}, \\
S_{F}^{\prime \prime}=\frac{\left[\left(\rho-\rho_{v}\right) g \sin \theta\right]^{2}}{T_{w} \mu}(\delta-y)^{2} .
\end{gathered}
$$

Integrating (11) with respect to $y$, the local entropy generation across the film thickness is obtained as

$$
\begin{gathered}
S^{\prime}=\int_{0}^{\delta} S^{\prime \prime} d y=S_{T}^{\prime}+S_{F}^{\prime}, \\
S_{T}^{\prime}=\int_{0}^{\delta} S_{T}^{\prime \prime} d y=\frac{k}{T_{w}^{2}} \frac{\Delta T^{2}}{\delta}, \\
S_{F}^{\prime}=\int_{0}^{\delta} S_{F}^{\prime \prime} d y=\frac{\left[\left(\rho-\rho_{v}\right) g \sin \theta\right]^{2}}{3 T_{w} \mu} \delta^{3} .
\end{gathered}
$$

Integrating (12) with respect to $\theta$, the total entropy generation within the condensate film can be derived as follows:

$$
\begin{gathered}
S=\int_{0}^{\pi} S^{\prime} d \theta=S_{T}+S_{F}, \\
S_{T}=\int_{0}^{\pi} \frac{k}{T_{w}^{2}} \frac{\Delta T^{2}}{\delta} d \theta=\frac{k \Delta T^{2}}{T_{w}^{2}} \int_{0}^{\pi} \frac{1}{\delta} d \theta \\
S_{F}=\int_{0}^{\pi} \frac{\left[\left(\rho-\rho_{v}\right) g \sin \theta\right]^{2}}{3 T_{w} \mu} \delta^{3} d \theta \\
=\frac{\left[\left(\rho-\rho_{v}\right) g\right]^{2}}{3 T_{w} \mu} \int_{0}^{\pi} \delta^{3} \sin ^{2} \theta d \theta .
\end{gathered}
$$
as

Let the characteristic entropy generation rate be defined

$$
S_{0}=\frac{k}{D}\left(\frac{\Delta T}{T_{w}}\right)^{2}
$$

The dimensionless total entropy generation can then be calculated as

$$
N=\frac{S}{S_{0}}=N_{T}+N_{F} .
$$

Substituting (16) and (17) into (13)-(15), the dimensionless entropy generation numbers for the heat transfer and fluid friction irreversibilities are obtained, respectively, as follows:

$$
\begin{gathered}
N_{T}=\int_{0}^{\pi} \frac{D}{\delta} d \theta \\
N_{F}=\frac{D T_{w}\left[\left(\rho-\rho_{v}\right) g\right]^{2}}{3 k \mu \Delta T^{2}} \int_{0}^{\pi} \delta^{3} \sin ^{2} \theta d \theta .
\end{gathered}
$$

Let the following dimensionless parameters be introduced:

$$
u_{0}=\frac{\left(\rho-\rho_{v}\right) g}{\mu} D^{2}, \quad \mathrm{Br}=\frac{\mu u_{0}^{2}}{k \Delta T}, \quad \Psi=\frac{\Delta T}{T_{w}} .
$$

Furthermore, let the dimensionless liquid film thickness be defined as

$$
\delta^{*}=\frac{\delta}{D}
$$

Substituting (19) into (18) and using (20), the dimensionless entropy generation number equations can be rewritten as

$$
\begin{gathered}
N_{T}=\int_{0}^{\pi} \frac{1}{\delta^{*}} d \theta \\
N_{F}=\frac{B r}{3 \Psi} \int_{0}^{\pi}\left(\delta^{*}\right)^{3} \sin ^{2} \theta d \theta .
\end{gathered}
$$

However, $N_{T}$ and $N_{F}$ cannot yet be derived since $\delta^{*}$ is unknown. 
To solve $\delta^{*}$, assume that the first law of thermodynamics and the mass conservation equation are coupled in the governing equations. The schematic presented at the top of Figure 1 shows the energy balance within a small control volume of liquid condensate extending from $x$ to $x+d x$. The energy flow entering the control volume is given as $\dot{E}_{\text {in }}=$ $\left.\left\{\int_{0}^{\delta} \rho u\left(h_{f g}+\mathrm{Cp}\left(T_{\text {sat }}-T\right)\right) d y\right\}\right|_{x}$, while that exiting the control volume is given as $\dot{E}_{\text {out }}=\left.\left\{\int_{0}^{\delta} \rho u\left(h_{f g}+\mathrm{Cp}\left(T_{\text {sat }}-T\right)\right) d y\right\}\right|_{x+d x}$. Furthermore, the net energy sucked out of the condensate layer is equal to $\dot{E}_{\text {suck }}=\left[\rho\left(h_{f g}+\mathrm{Cp} \Delta T\right) v_{w}\right] d x$, while the heat transferred into the condensate layer as a result of conduction is equal to $\dot{E}_{\text {cond }}=-k(\partial T / \partial y) d x$. Therefore, the overall energy balance in the liquid film, that is, $\dot{E}_{\text {in }}-\dot{E}_{\text {out }}-\dot{E}_{\text {suck }}=$ $\dot{E}_{\text {cond }}$, can be expressed as

$$
\begin{aligned}
\frac{d}{d x}\left\{\int_{0}^{\delta} \rho u\left(h_{f g}+\operatorname{Cp}\left(T_{\text {sat }}-T\right)\right) d y\right\} d x \\
+\left[\rho\left(h_{f g}+\operatorname{Cp} \Delta T\right) v_{w}\right] d x=k \frac{\partial T}{\partial y} d x
\end{aligned}
$$

where the first term on the left-hand side of (23) represents the net energy flux across the liquid film (i.e., from $x$ to $x+$ $d x$ ), while the second term represents the net energy sucked out of the condensate layer.

Substituting (6) and (7) into (23) and using the correlation $d x=(D / 2) d \theta,(23)$ can be rewritten as

$$
\begin{gathered}
\frac{\rho\left(\rho-\rho_{v}\right) g\left(h_{f g}+(3 / 8) \mathrm{Cp} \Delta T\right)}{3 \mu} \frac{2 d}{D d \theta}\left\{\delta^{3} \sin \theta\right\} \\
+\rho\left(h_{f g}+\mathrm{Cp} \Delta T\right) v_{w}=k \frac{\Delta T}{\delta} .
\end{gathered}
$$

For analytical convenience, let the following dimensionless parameters be introduced:

$$
\begin{gathered}
\mathrm{Ja}=\frac{\mathrm{Cp} \Delta T}{h_{f g}+(3 / 8) \mathrm{Cp} \Delta T}, \quad \operatorname{Pr}=\frac{\mu \mathrm{Cp}}{k}, \\
\mathrm{Ra}=\frac{\rho\left(\rho-\rho_{v}\right) g \operatorname{Pr} D^{3}}{\mu^{2}}, \\
\operatorname{Re}_{w}=\frac{\rho v_{w} D}{\mu}, \quad S_{w}=\left(1+\frac{5}{8} \mathrm{Ja}\right) \mathrm{Re}_{w} \frac{\operatorname{Pr}}{\operatorname{Ra}} .
\end{gathered}
$$

Substituting (25) and (20) into (24) yields the following:

$$
\delta^{*} \frac{d}{d \theta}\left(\delta^{* 3} \sin \theta\right)+\frac{3}{2} S_{w} \delta^{*}=\frac{3}{2} \frac{\mathrm{Ja}}{\mathrm{Ra}} .
$$

The boundary conditions for the liquid film thickness are given as

$$
\begin{gathered}
\frac{d \delta^{*}}{d \theta}=0, \quad \text { at } \theta=0, \\
\delta^{*} \longrightarrow \infty, \quad \text { at } \theta=\pi .
\end{gathered}
$$

Assuming that the wall suction effect is ignored (i.e., $S_{w}=0$ ), (26) can be expressed as

$$
\left.\delta^{*}\right|_{S_{w}=0} \frac{d}{d \theta}\left(\left(\left.\delta^{*}\right|_{S_{w}=0}\right)^{3} \sin \theta\right)=\frac{3}{2} \frac{\mathrm{Ja}}{\mathrm{Ra}},
$$

where $\left.\delta^{*}\right|_{S w=0}$ is the dimensionless local liquid film thickness in the absence of wall suction.

Using the separation of variables method, the analytical solution for the dimensionless local film thickness can be derived as

$$
\left.\delta^{*}\right|_{S_{w}=0}=\sin ^{-1 / 3} \theta\left(2 \frac{\mathrm{Ja}}{\mathrm{Ra}}\right)^{1 / 4}\left(\int_{0}^{\theta} \sin ^{1 / 3} \theta d \theta\right)^{1 / 4} .
$$

The value of $\left.\delta^{*}\right|_{S_{w}=0}$ along the surface of the horizontal tube can then be calculated by integrating $\int_{0}^{\theta} \sin ^{1 / 3} \theta d \theta$.

Let the effect of wall suction on the thickness of the condensate layer be characterized by the following film thickness reduction ratio:

$$
S_{f}=1-\frac{\delta^{*}}{\left.\delta^{*}\right|_{S_{w}=0}} .
$$

Since $\delta^{*} \leq\left.\delta^{*}\right|_{S_{w}=0}$, the value of $S_{f}$ falls within the range of $0 \leq S_{f} \leq 1$. Substituting (30) into (28) the following equation for $S_{f}$ is obtained:

$$
\begin{aligned}
& 3\left(\left.\delta^{*}\right|_{S_{w}=0}\right)^{4} \sin \theta\left(1-S_{f}\right)^{3} \frac{d f}{d \theta} \\
& +\left.\delta^{*}\right|_{S_{w}=0} \frac{d}{d \theta}\left(\left(\left.\delta^{*}\right|_{S_{w}=0}\right)^{3} \sin \theta\right) \\
& \quad \times\left(S_{f}^{4}-4 S_{f}^{3}+6 S_{f}^{2}-4 S_{f}\right) \\
& +\left.\frac{3}{2} \delta^{*}\right|_{S_{w}=0}\left(1-S_{f}\right) \times S_{w}=0 .
\end{aligned}
$$

Setting $\theta$ to 0 , the initial condition, $S_{f}(0)$, is obtained as

$$
A S_{f}^{4}(0)+B S_{f}^{3}(0)+C S_{f}^{2}(0)+D S_{f}(0)+E=0,
$$

where

$$
\begin{gathered}
A=\left(\left.\delta^{*}\right|_{S_{w}=0, \theta=0}\right)^{4}, \\
B=-4 A, \\
C=6 A, \\
D=-4 A-\frac{3}{2}\left(\left.\delta^{*}\right|_{S_{w}=0, \theta=0}\right) \times S_{w}, \\
E=\frac{3}{2}\left(\left.\delta^{*}\right|_{S_{w}=0, \theta=0}\right) \times S_{w} .
\end{gathered}
$$

The exact value of $S_{f}(0)$ in (32) can be determined using the bisection method [20]. The variation of $S_{f}$ in the $\theta$ direction can then be obtained by substituting $S_{f}(0)$ and (29) 
into (31). Furthermore, the dimensionless local liquid film thickness can be derived as

$$
\begin{aligned}
\delta^{*}(\theta) & =\left(1-S_{f}\right) \times\left.\delta^{*}\right|_{S_{w}=0} \\
& =\left(1-S_{f}\right) \sin ^{-1 / 3} \theta\left(2 \frac{\mathrm{Ja}}{\mathrm{Ra}}\right)^{1 / 4}\left(\int_{0}^{\theta} \sin ^{1 / 3} \theta d \theta\right)^{1 / 4} .
\end{aligned}
$$

In general, the local Nusselt number is given by

$$
\mathrm{Nu}_{\theta}=\frac{h_{\theta} D}{k}
$$

where

$$
h_{\theta}=\frac{k}{\delta}
$$

Substituting (34) into (35), the local Nusselt number can be rewritten as

$$
\begin{aligned}
\mathrm{Nu}_{\theta} & =\frac{1}{\delta^{*}(\theta)} \\
& =\left(\frac{\mathrm{Ra}}{\mathrm{Ja}}\right)^{1 / 4} \frac{\sin ^{1 / 3} \theta\left(4 \int_{0}^{\theta} \sin ^{1 / 3} \theta d \theta\right)^{-1 / 4}}{\left(1-S_{f}\right)} .
\end{aligned}
$$

The mean Nusselt number can then be derived as

$$
\begin{aligned}
\overline{\mathrm{Nu}} & =\frac{1}{\pi} \int_{0}^{\pi} \frac{1}{\delta^{*}(\theta)} d \theta \\
& =\frac{1}{\pi}\left(\frac{\mathrm{Ra}}{\mathrm{Ja}}\right)^{1 / 4} \int_{0}^{\pi} \frac{\sin ^{1 / 3} \theta\left(4 \int_{0}^{\theta} \sin ^{1 / 3} \theta d \theta\right)^{-1 / 4}}{\left(1-S_{f}\right)} d \theta .
\end{aligned}
$$

Comparing (21) and (38), the dimensionless entropy generation due to heat transfer, $N_{T}$, can be obtained as

$$
N_{T}=\int_{0}^{\pi} \frac{1}{\delta^{*}} d \theta=\pi \times \overline{\mathrm{Nu}}
$$

\section{Results and Discussion}

In the present study, the working fluid was assumed to be water vapor (one of the most commonly used liquids in engineering applications). Moreover, for the case where the wall section effect was ignored (i.e., the suction Reynolds number velocity $\operatorname{Re}_{w}$ was set equal to zero), the mean Nusselt number was derived by substituting $S_{f}=0$ into (38); that is,

$$
\left.\overline{\mathrm{Nu}}\right|_{S_{w}=0}=\frac{1}{\pi}\left(\frac{\mathrm{Ra}}{\mathrm{Ja}}\right)^{1 / 4} \int_{0}^{\pi} \sin ^{1 / 3} \theta\left(4 \int_{0}^{\theta} \sin ^{1 / 3} \theta d \theta\right)^{-1 / 4} d \theta .
$$

In addition, an explicit formulation for the mean Nusselt number was obtained by using a simple numerical method
[20] to deal with the integration term $\int_{0}^{\pi} \sin ^{1 / 3} \theta\left(4 \int_{0}^{\theta} \sin ^{1 / 3}\right.$ $\theta d \theta)^{-1 / 4} d \theta$ in (32), yielding

$$
\left.\overline{\mathrm{Nu}}\right|_{S_{w}=0}=1.224 \times\left(\frac{\mathrm{Ra}}{\mathrm{Ja}}\right)^{1 / 4} .
$$

Yang and Chen [6] used a novel transformation method to investigate the problem of film condensation on a horizontal elliptical tube in the absence of wall suction. However, the parameters defined in [6] differ from those used in the current analysis. Therefore, to enable a direct comparison to be made with the present results, the formulations presented in [6] should be transformed from their original formats and expressed in terms of the current parameters. Based on the derivations presented in [6], the mean Nusselt number for a circular tube should be transformed as

$$
\overline{\mathrm{Nu}}=1.225 \times\left(\frac{\mathrm{Ra}}{\mathrm{Ja}}\right)^{1 / 4} \text {. }
$$

It is evident that a good agreement exists between (41) and (42). Thus, the basic validity of the analytical model proposed in the present study is confirmed.

As shown in (17), the dimensionless entropy generation in the condensate layer on the horizontal tube is induced by both heat transfer and liquid film flow friction. In (19), $u_{0}, \mathrm{Br}$, and $\Psi$ are defined as $u_{0}=\left(\left(\rho-\rho_{v}\right) g / \mu\right) D^{2}, \mathrm{Br}=\mu u_{0}^{2} / k \Delta T$, and $\Psi=\Delta T / T_{w}$, respectively. It thus follows that $(\mathrm{Br} / \psi)=$ $\left(\left(\rho-\rho_{v}\right)^{2} g^{2} D^{4} / \mu k T_{w}\right)$. For the water vapor considered in the present study, $\mathrm{Br} / \psi$ has a value of 5 given a tube diameter of $D=3 / 8$ inches and a temperature of $100^{\circ} \mathrm{C}$. Figure 2 shows that the dimensionless entropy generation caused by heat transfer, $N_{T}$, increases with an increasing suction parame-ter, $S_{w}$. This finding is reasonable since the thickness of the liquid film reduces with an increasing suction effect and therefore improves the heat transfer performance. Moreover, the finding is consistent with (38) and (39), which show that $N_{T}$ is equal to $\pi$ times the mean Nusselt number $\overline{\mathrm{Nu}}$, and $\overline{\mathrm{Nu}}$ increases with increasing $S_{f}$. In addition, Figure 2 shows that the dimensionless entropy generation due to heat transfer, $N_{T}$, is proportional to $(\mathrm{Ra} / \mathrm{Ja})^{1 / 4}$, as predicted by both (41) and (42).

Figure 3 shows that the dimensionless entropy generation due to liquid film flow friction, $N_{F}$, decreases with an increasing suction parameter $S_{w}$. Again, this finding is reasonable since as the suction parameter increases, a greater amount of liquid is sucked into the porous tube. Consequently, the quantity of liquid condensate on the tube surface is reduced, and thus the entropy generation caused by liquid film flow friction also reduces. Figure 3 shows that the dimensionless entropy generation due to liquid film flow friction, $N_{F}$, reduces as $(\mathrm{Ra} / \mathrm{Ja})^{1 / 4}$ increases (i.e., an opposite tendency to that observed for $N_{T}($ or $\overline{\mathrm{Nu}})$ ). This result is reasonable since a larger value of $N_{T}$ (or $\overline{\mathrm{Nu}}$ ) implies the existence of a thinner condensate film on the tube surface and hence a lower liquid film flow friction.

As discussed above, the dimensionless entropy generation due to heat transfer increases with increasing $(\mathrm{Ra} / \mathrm{Ja})$, whereas the dimensionless entropy generation due to liquid 


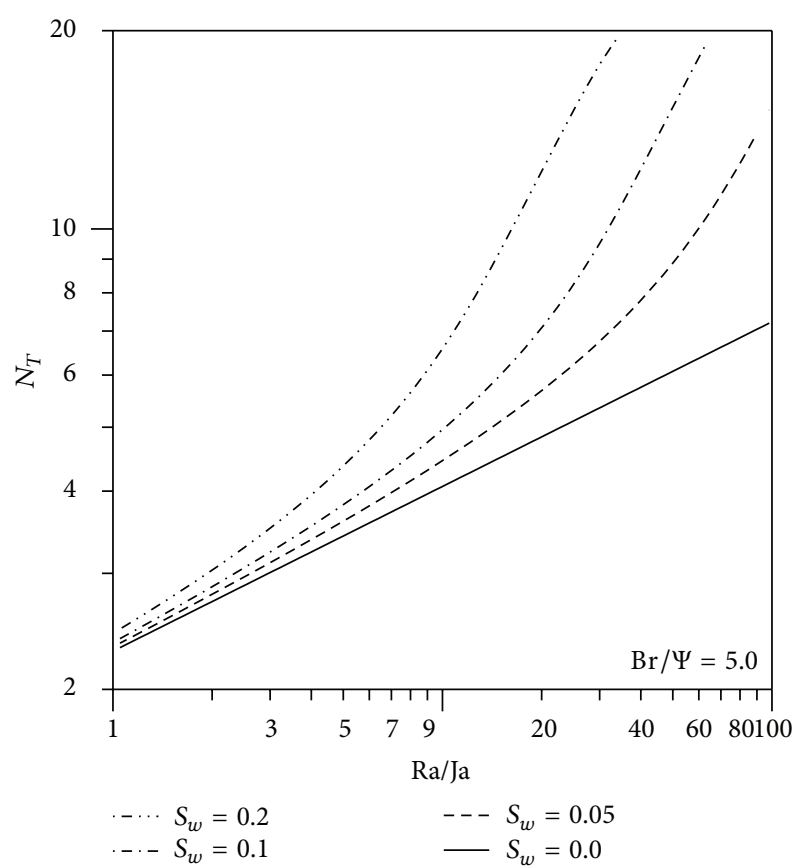

FIGURE 2: Dimensionless entropy generation due to heat transfer versus $\mathrm{Ra} / \mathrm{Ja}$ as function of $S_{w}$.

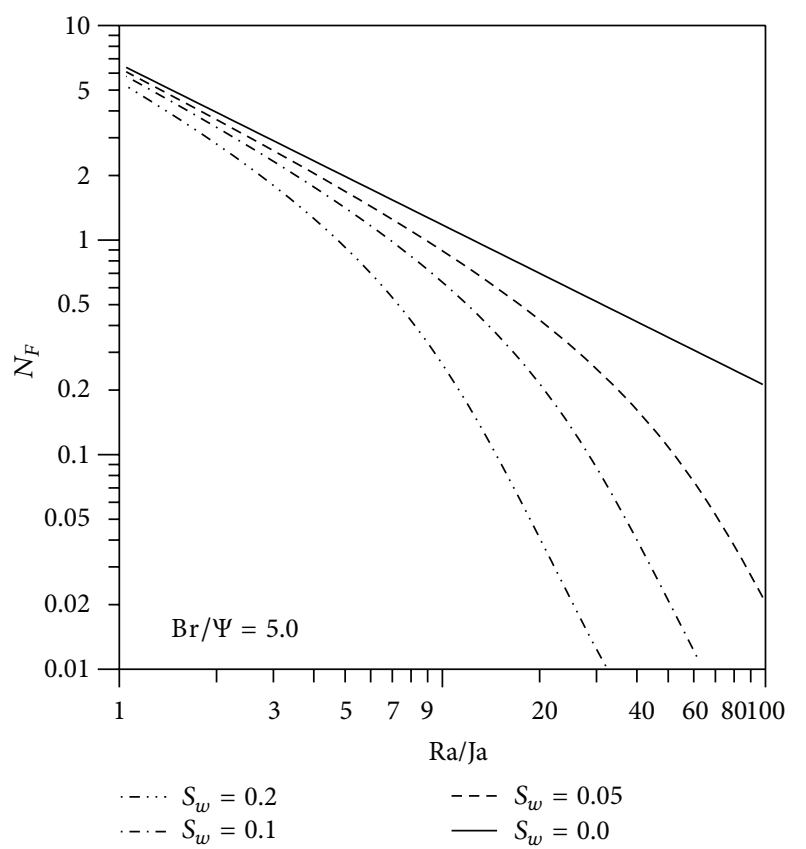

Figure 3: Dimensionless entropy generation due to liquid film flow friction versus $\mathrm{Ra} / \mathrm{J}$ a as function of $S_{w}$.

film flow friction decreases. As a result, it follows that there should exist a minimum value of the dimensionless total entropy generation, $N$, at a certain value of $(\mathrm{Ra} / \mathrm{Ja})$. Figure 4 shows the variation of $N$ with $(\mathrm{Ra} / \mathrm{Ja})$ as a function of the wall suction parameter $S_{w}$ for a constant $\mathrm{Br} / \psi=5$. It is seen that the minimum value of $N$ occurs at $(\mathrm{Ra} / \mathrm{Ja})_{\text {opt }}=8.56,6.70$,

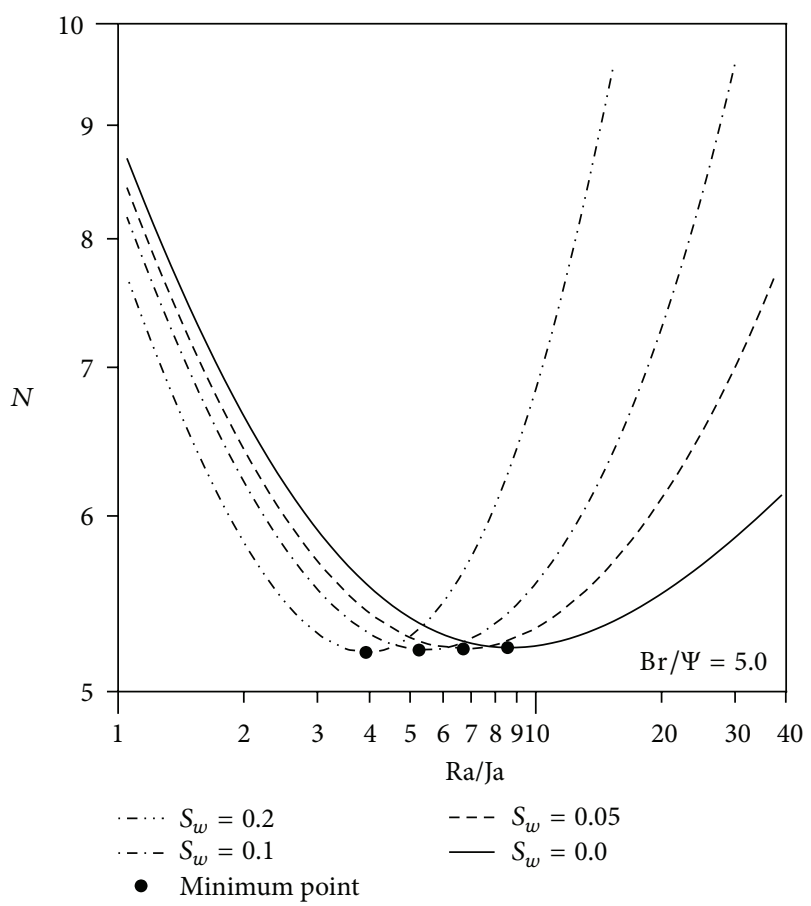

FIGURE 4: Dimensionless total entropy generation versus $\mathrm{Ra} / \mathrm{Ja}$ as function of $S_{w}$.

5.25 , and 3.92 given wall suction parameter values of $S_{w}=0$, $0.05,0.1$, and 0.2 , respectively. The corresponding minimum values of $N$ are determined from (17) to be 5.233, 5.226, 5.220, and 5.208 , respectively.

Let the respective effects of the liquid film flow friction irreversibility and heat transfer irreversibility on the entropy generation rate be quantified by an irreversibility ratio $N_{F}$ / $N_{T}$. Clearly, the entropy generation rate is dominated by the liquid film flow friction irreversibility when $N_{F} / N_{T}>1$, but by the heat transfer irreversibility when $N_{F} / N_{T}<1$. Figure 5 shows that, for wall suction parameters of $S_{w}=0,0.05,0.1$, and 0.2 , the contribution of the heat transfer irreversibility to the entropy generation rate is greater than that of the liquid film flow friction irreversibility (i.e., $N_{F} / N_{T}<1$ ) when $\mathrm{Ra} / \mathrm{Ja} \geq 2.90,2.54,2.28$, and 1.88 , respectively. In other words, a higher value of $S_{w}$ results in a higher heat transfer performance and therefore broadens the range of $\mathrm{Ra} / \mathrm{Ja}$ over which the heat transfer irreversibility dominates. In practical applications, $\mathrm{Ra} / \mathrm{Ja}$ has a value of more than 10 . Thus, as shown in Figure 5, the total entropy generation rate is dominated by the heat transfer process between the saturated vapor and the wall.

\section{Conclusion}

This study has examined the entropy generation rate in a laminar condensate film on a horizontal tube with wall suction effects. It has been shown that the mean Nusselt number varies as a function of $\mathrm{Ra} / \mathrm{Ja}$. Moreover, the dimensionless entropy generation number induced by heat transfer irreversibility is equal to $\pi$ times the mean Nusselt number, while 


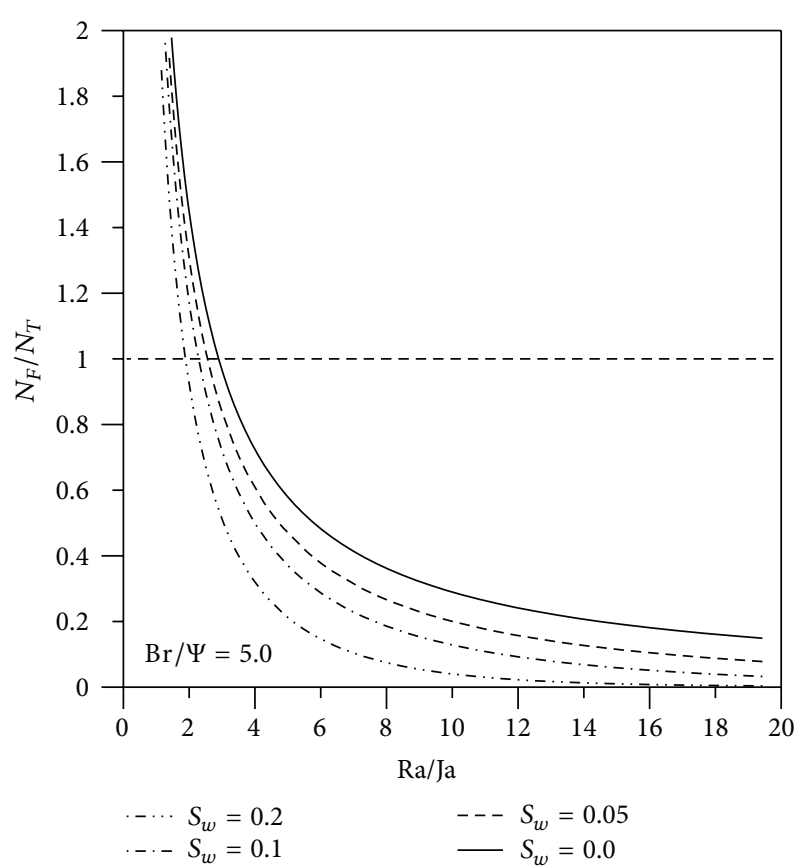

FIGURE 5: Irreversibility ratio versus $\mathrm{Ra} / \mathrm{Ja}$ as function of $S_{w}$.

the dimensionless entropy generation number induced by film flow friction irreversibility is equal to $(\mathrm{Br} / 3 \Psi) \int_{0}^{\pi}\left(\delta^{*}\right)^{3}$ $\sin ^{2} \theta d \theta$. Finally, it has been shown that the presence of a wall suction effect reduces the thickness of the liquid film, thereby increasing the heat transfer coefficient and entropy generation due to heat transfer but decreasing the entropy generation due to liquid film flow friction.

\section{Nomenclature}

Br: Brinkman number defined in (19)

Cp: Specific heat at constant pressure

D: Diameter of circular tube

g: Acceleration of gravity

$h$ : Heat transfer coefficient

$h_{f g}$ : Heat of vaporization

Ja: Jakob number defined in (25)

$k$ : Thermal conductivity

$N$ : Dimensionless overall entropy generation number defined in (17)

Nu: Nusselt number defined in (35)

Pr: Prandtl number defined in (25)

Ra: Rayleigh number defined in (25)

$\mathrm{Re}_{w}$ : Suction Reynolds number defined in (25)

$S^{\prime \prime}$ : Local entropy generation rate defined in (8)

$S: \quad$ Overall entropy generation rate defined in (13)

$S_{f}:$ Film thickness reduction ratio defined in (30)

$S_{0}$ : Characteristic entropy generation rate defined in (16)

$S_{w}$ : Suction parameter defined in (25)

$T: \quad$ Temperature

$\Delta T$ : Saturation temperature minus wall temperature $u$ : Velocity component in $x$-direction

$v$ : Velocity component in $y$-direction.

Greek Symbols

$\delta$ : Condensate film thickness

$\mu$ : Liquid viscosity

$\rho$ : Liquid density

$\theta$ : Angle measured from top of tube

$\psi$ : Dimensionless temperature difference defined in (19).

Superscripts

—: Average quantity

*: Dimensionless variable.

Subscripts

min: Minimum quantity

sat: Saturation property

$w$ : Quantity at wall.

\section{Conflict of Interests}

The author declares that there is no conflict of interests regarding the publication of this paper.

\section{Acknowledgment}

This study was supported by the National Science Council of Taiwan under Grant no. NSC 101-2221-E-218-016.

\section{References}

[1] W. Nusselt, "Die oberflachen Kondensation des Wasserdampes," Zeitsehrift des Vereines Deutscher Ingenieure, vol. 60, no. 2, pp. 541-546, 1916.

[2] V. D. Popov, "Heat Transfer during vapor condensation on a horizontal surfaces," TrudyKiev. Teknol.InstPishch Prom., vol. 11, pp. 87-97, 1951.

[3] G. Leppert and B. Nimmo, "Laminar film condensation on surface normal to body or inertial forces," Transactions of the ASME, Journal of Heat Transfer, vol. 80, pp. 178-179, 1968.

[4] B. Nimmo and G. Leppert, "Laminar film condensation on a finite horizontal surface," in Proceedings of the 4th International Heat Transfer Conference, pp. 402-403, 1970.

[5] T. Shigechi, N. Kawae, Y. Tokita, and T. Yamada, "Film condensation heat transfer on a finite-size horizontal plate facing upward," JSME Series B, vol. 56, pp. 205-210, 1990.

[6] S. A. Yang and C. K. Chen, "Role of surface tension and ellipticity in laminar film condensation on a horizontal elliptical tube," International Journal of Heat and Mass Transfer, vol. 36, no. 12, pp. 3135-3141, 1993.

[7] H.-P. Hu and C.-K. Chen, "Simplified approach of turbulent film condensation on an inclined elliptical tube," International Journal of Heat and Mass Transfer, vol. 49, no. 3-4, pp. 640-648, 2006. 
[8] A. Bejan, "Entropy generation minimization: the method and its applications," in Proceedings of the ASME-ZSITS International Thermal Science Seminar, pp. 7-17, Bled, Slovenia, June 2000.

[9] A. Bejan, Entropy Generation Minimization, chapter 4, CRC Press, Boca Raton, Fla, USA, 1996.

[10] A. Bejan, "A study of entropy generation in fundamental convective heat transfer," Journal of Heat Transfer, vol. 101, no. 4, pp. 718-725, 1979.

[11] S. Saouli and S. Aïboud-Saouli, "Second law analysis of laminar falling liquid film along an inclined heated plate," International Communications in Heat and Mass Transfer, vol. 31, no. 6, pp. 879-886, 2004.

[12] O. B. Adeyinka and G. F. Naterer, "Optimization correlation for entropy production and energy availability in film condensation," International Communications in Heat and Mass Transfer, vol. 31, no. 4, pp. 513-524, 2004.

[13] S.-C. Dung and S.-A. Yang, "Second law based optimization of free convection film-wise condensation on a horizontal tube," International Communications in Heat and Mass Transfer, vol. 33, no. 5, pp. 636-644, 2006.

[14] G.-C. Li and S.-A. Yang, "Thermodynamic analysis of free convection film condensation on an elliptical cylinder," Journal of the Chinese Institute of Engineers, vol. 29, no. 5, pp. 903-908, 2006.

[15] T. B. Chang and F. J. Wang, "An analytical investigation into the Nusselt number and entropy generation rate of film condensation on a horizontal plate," Journal of Mechanical Science and Technology, vol. 22, no. 11, pp. 2134-2141, 2008.

[16] T.-B. Chang, W.-Y. Yeh, and G.-L. Tsai, "Film condensation on horizontal tube with wall suction effects," Journal of Mechanical Science and Technology, vol. 23, no. 12, pp. 3399-3406, 2010.

[17] T.-B. Chang and W.-Y. Yeh, "Theoretical investigation into condensation heat transfer on horizontal elliptical tube in stationary saturated vapor with wall suction," Applied Thermal Engineering, vol. 31, no. 5, pp. 946-953, 2011.

[18] T. B. Chang, "Effects of surface tension on laminar filmwise condensation on a horizontal plate in a porous medium with suction at the wall," Chemical Engineering Communications, vol. 195, no. 7, pp. 721-737, 2008.

[19] W. M. Rohsenow, "Heat transfer and temperature distribution in laminar film condensation," Transactions of the ASME, Journal of Heat Transfer, vol. 78, pp. 1645-1648, 1956.

[20] M. L. James, G. M. Smith, and J. C. Wolford, Applied Numerical Methods for Digital Computation, Happer \& Row, New York, NY, USA, 3rd edition, 1985. 


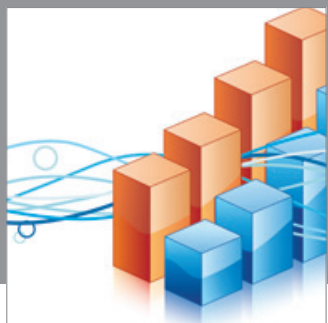

Advances in

Operations Research

mansans

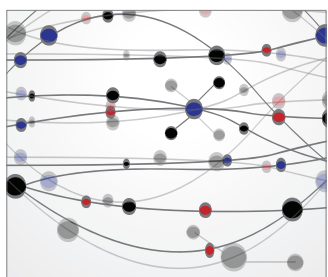

The Scientific World Journal
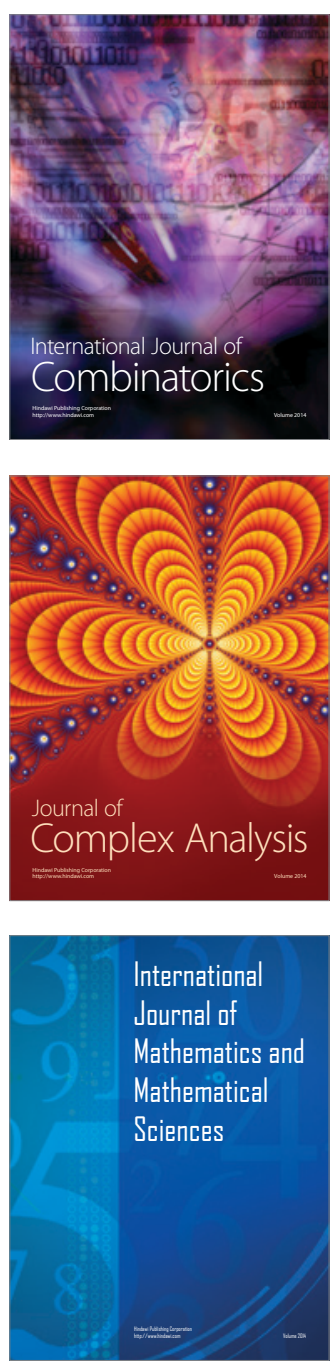
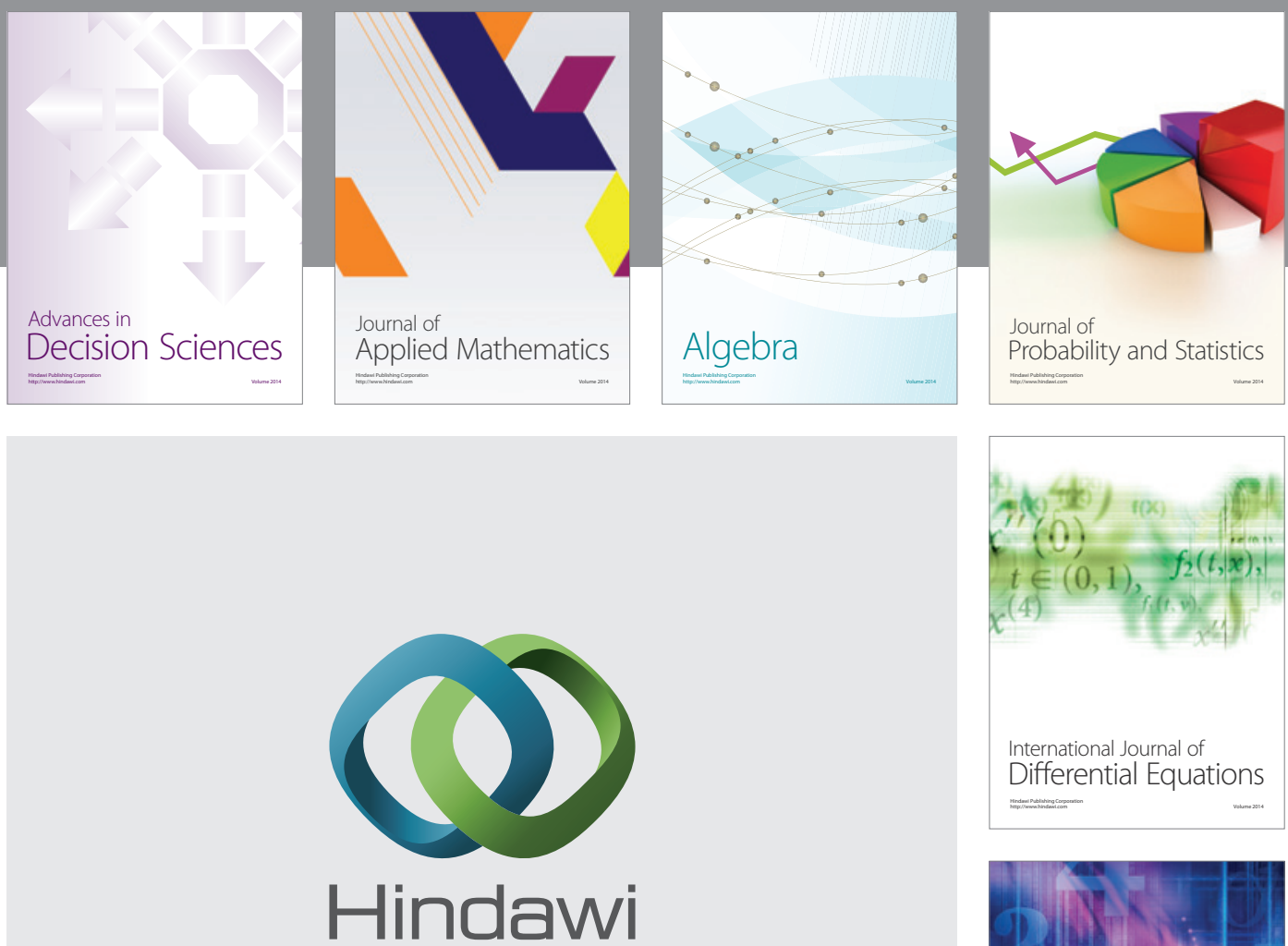

Submit your manuscripts at http://www.hindawi.com
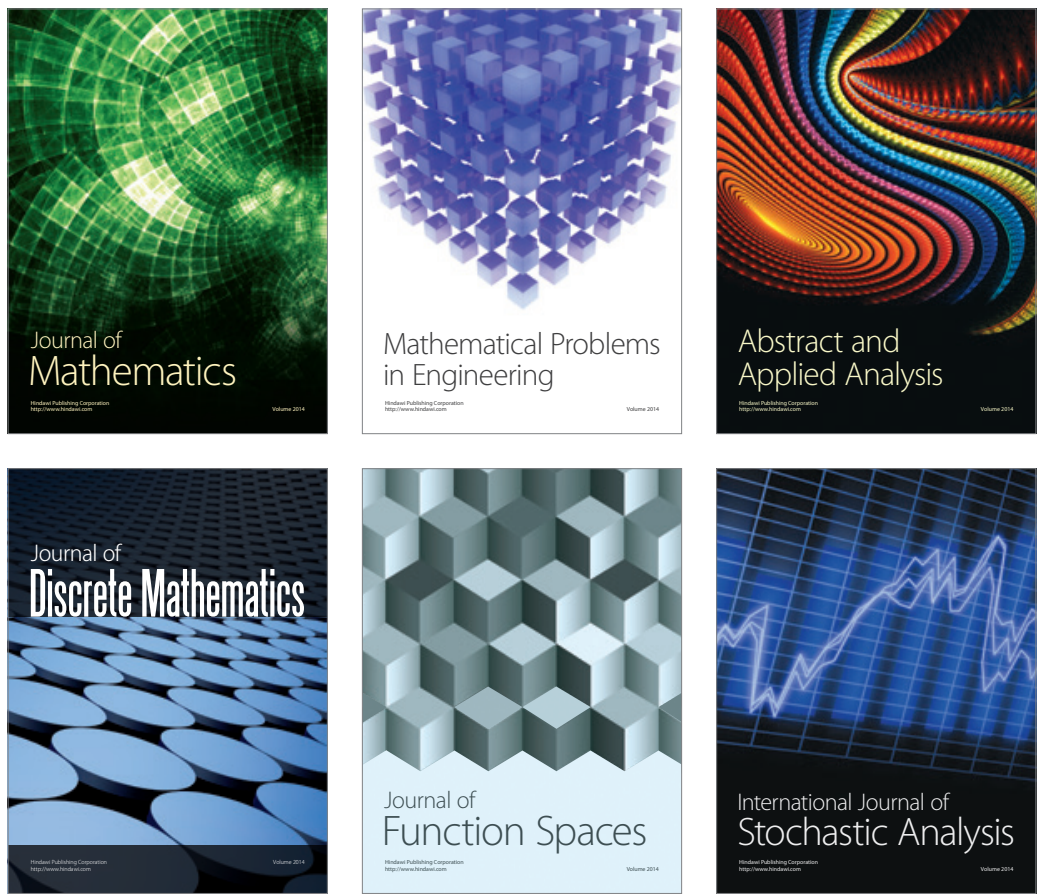

Journal of

Function Spaces

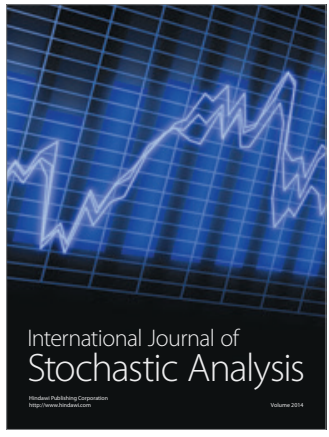

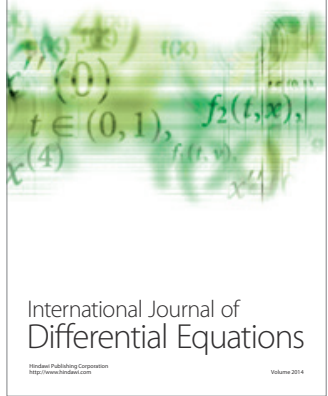
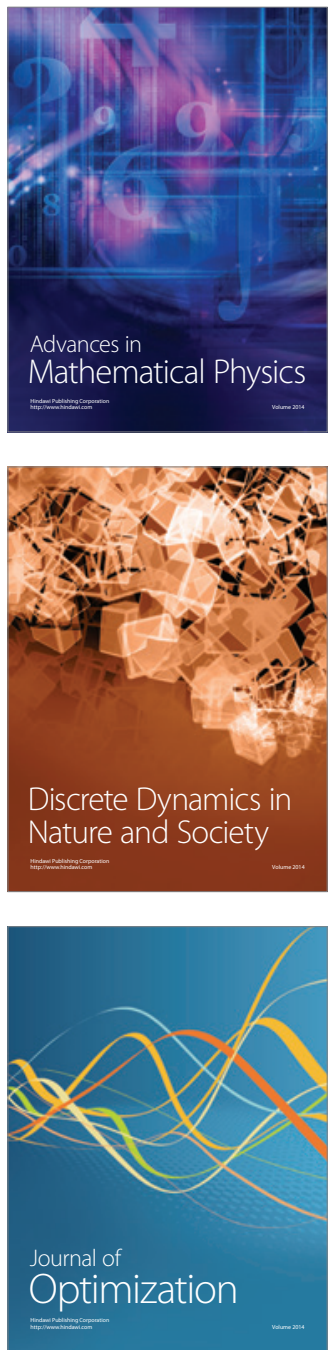